\title{
Constituents of the Flower of Maxillaria tenuifolia and Their Anti-Diabetic Activity
}

\author{
Chia-Ying Li \\ Department of Applied Chemistry, National Pingtung University, Pingtung City, Pingtung County \\ 900393, Taiwan
}

(Received June08, 2021; Revised August 10, 2021; Accepted August 12, 2021)

\begin{abstract}
The EtOAc extract of the flower of Maxillaria tenuifolia, which had shown potent $\alpha$-glucosidase inhibitory, was subjected to activity-guided isolation to yield four compounds, 3,4-dihydroxy benzoic acid methyl ester (1), flavanthridin (2), vanillic acid (3) and mangiferin (4). Their structures were ascertained by comparison of their physical and spectroscopic properties with those reported in the literature. Among them, flavanthridin (2), vanillic acid (3) and mangiferin (4) showed significant $\alpha$-glucosidase inhibitory activity compared to acarbose at the concentration $1.0 \mathrm{mg} / \mathrm{mL}$. Besides, 3,4-dihydroxy benzoic acid methyl ester (1) and mangiferin (4) also showed more effective in against the peroxidation of linoleic acid in an aqueous system than trolox. These results indicated that the EtOAc extract of M. tenuifolia and the related constituents might have anti-diabetic effect by suppressing carbohydrate disintegration and could prevent damage to organisms by oxidative stress.
\end{abstract}

Keywords: $\alpha$-Glucosidase; diabetes; Maxillaria tenuifolia; antioxidant. () 2021 ACG Publications. All rights reserved.

\section{Plant Source}

Maxillaria tenuifolia Lindl. (Orchidaceae) were obtained from Lan Hui Biotech Co. (Taiwan) and verified by Dr. Y. Y. Hsiao. A voucher specimen (NPTU140530) was deposited in the Herbarium of National Pingtung University, Pingtung, Taiwan.

\section{Previous Studies}

Maxillaria tenuifolia Lindl., also known as the "coconut orchid", is an orchid belonging to the Epidendroideae subfamily ranging from Mexico to Nicaragua. These plants are easy to grow if the environment keeps moist and provides the good air movement in a high-light field. Maxillaria tenuifolia is a longtime favorite plant because of its strong coconut odor. This is a rare property

*Corresponding author: E-Mail: cyli@ mail.nptu.edu.tw; Phone: +886-8-7663800 ext. 33256 


\section{Anti-diabetic activity of $M$. tenuifolia}

because most of the orchids are scentless to a human nose. Previous chemical investigation of Maxillaria species discussed the isolation and structure elucidation of several phenanthrene derivatives $[1,2]$. Although the floral volatile compounds of $M$. tenuifolia have been investigated by using headspace-solid phase microextraction coupled to gas chromatography and mass spectrometry $[3,4]$, the non-volatile constituents of $M$. tenuifolia have not been subjected through the phytochemical analysis.

The rapidly increasing diabetes mellitus is becoming a serious threat to mankind's health in all parts of the world. The control and treatment of diabetes and its complications mainly depend on the chemical or biochemical agents, but it has never been reported that someone is recovered totally from diabetes [5]. The $\alpha$-glucosidase inhibitor is effective in treating diabetes mellitus and widely used in patients with type- 2 diabetes. $\alpha$-Glucosidase is an enzyme of the intestinal brush border such as hydrolyses terminal, non-reducing 1,4-linked $\alpha$-D-glucose residues and releases $\alpha$-D-glucose. Inhibition of $\alpha$-glucosidase diminishes glucose resorption and postprandial hyperglycemia [6]. Acarbose has been shown the significant improvement of glycemic control in type II diabetes patients [7]. Likewise, herbal inhibitors of $\alpha$-glucosidase could have the potential ability to decrease postprandial hyperglycemia.

In our ongoing investigation of $\alpha$-glucosidase inhibitors form the natural source, the EtOAc extract of $M$. tenuifolia (flower) showed significant inhibition of $\alpha$-glucosidase ( $82.9 \%$ inhibition at 1 $\mathrm{mg} / \mathrm{mL}$ ), indicated that the EtOAc extract of the flower of $M$. tenuifolia may function as an antihyperglycemic. To understand the inhibitive principle more clearly and to develop an antihyperglycemic drug, the large-scale extraction and fractionation of the flower of M. tenuifolia were undertaken.

\section{Present Study}

This paper dealt with the isolation and identification of compounds $\mathbf{1}-\mathbf{4}$ from the flower of Maxillaria tenuifolia and analyzed the inhibitory activity of the isolates in relation to acarbose towards $\alpha$-glucosidase. Furthermore, the antioxidative properties of isolated constituents were also discussed.

Equipment: Melting points were measured on a Yanagimoto MP-S3 micro melting point apparatus and are uncorrected. The UV spectra were recorded on a Hitachi U-3900 spectrophotometer in $\mathrm{MeOH}$ solution. The FT-IR spectra were measured on an Agilent Technologies Cary-630 spectrophotometer as $\mathrm{KBr}$ disks. The ${ }^{1} \mathrm{H}-\mathrm{NMR}(400 \mathrm{MHz})$ and ${ }^{13} \mathrm{C}-\mathrm{NMR}(100 \mathrm{MHz})$ spectra were recorded on a Varian400 Unity Plus spectrometer. Chemical shifts are shown in $\delta$ values with tetramethylsilane as an internal reference. $\alpha$-Glucosidase (EC 3.2.1.20) from Baker's yeast (Saccharomyces cerevisiae) and $p$-nitrophenyl $\alpha$-D-glucopyranoside ( $p$ NPG) as a synthetic substrate were purchased from SigmaAldrich (St. Louis, MO, USA). Acarbose (Glucobay®; Bayer Vital, Leverkusen, Germany) as a synthetic inhibitor of $\alpha$-glucosidase was obtained from a local pharmacy.

Extraction and Separation: The fresh flowers of Maxillaria tenuifolia $(2.8 \mathrm{~kg})$ were soaked with EtOAc $(5 \mathrm{~L} \times 3)$ at room temperature, and the combined extracts were concentrated under reduced pressure to give a deep brown syrup (MTE, $47.1 \mathrm{~g}$ ). The extract was directly chromatographed on a silica gel column by elution with a gradient of $\mathrm{CHCl}_{3} / \mathrm{MeOH}$ to afford ten fractions. Fr. 3 underwent column chromatographic separation over silica gel using $\mathrm{CHCl}_{3} / \mathrm{Me}_{2} \mathrm{CO}$ (19:1) as an eluent to yield 3,4-dihydroxy benzoic acid methyl ester (1) $(20 \mathrm{mg}$ ) and flavanthridin (2) (91 mg). Fr. 9 was rechromatographed on a silica gel column and eluted with $\mathrm{CHCl}_{3} / \mathrm{MeOH}(9: 1)$ to give vanillic acid (3) (443 mg). Fr. 10 was recrystallization by EtOAc/MeOH (2:1) to afford mangiferin (4) (14.6 g).

Assay for $\alpha$-Glucosidase Inhibitory Activity: Based on the chromogenic method described by Kim et $a l$. [8], we made slight modifications for the $\alpha$-glucosidase inhibitory assay by using $\alpha$-glucosidase from Baker's yeast. The substrate solution $p$-nitrophenyl $\alpha$-D-glucopyranoside was prepared in $0.1 \mathrm{M}$ phosphate buffer, adjusted to $\mathrm{pH} 6.9$, to simulate a model of intestinal fluid. Briefly, $\alpha$-glucosidase was dissolved in $0.1 \mathrm{M}$ phosphate buffer, $\mathrm{pH} 6.9$, to yield a $1 \mathrm{U} / \mathrm{mL}$ stock-solution and pre-incubated 
for $10 \mathrm{~min}$ at $37{ }^{\circ} \mathrm{C}$ with $100 \mu \mathrm{L}$ of the respective test solution (DMSO solutions of extracts or compounds at $1.0 \mathrm{mg} / \mathrm{mL}$ concentration). The enzymatic reaction was initiated by adding $0.95 \mathrm{mM}$ $p N P G$ and the reaction mixture was incubated for another $20 \mathrm{~min}$ at $37^{\circ} \mathrm{C}$. The catalytic reaction was terminated by addition of a $1 \mathrm{M} \mathrm{Na}_{2} \mathrm{CO}_{3}$ solution. Activity of $\alpha$-glucosidase was determined by measuring the product $p$-nitrophenol released from $p$ NPG at $405 \mathrm{~nm}$ using a Synengy 2 Microplate Reader from Biotek.

Assay for Antioxidative Activity: In the present study, the ferric thiocyanate method was routinely used for the measurement of the antioxidative activity according to Chen et al. with a slight modification [9]. For oxidation, $1.0 \mathrm{~mL}$ of $0.1 \mathrm{M}$ sodium phosphate buffer $(\mathrm{pH} 7.0), 0.5 \mathrm{~mL}$ of distilled water, and $1.0 \mathrm{~mL}$ of $50 \mathrm{mM}$ linoleic acid in ethanol $(99.5 \%)$ were mixed in a glass test tube ( $5 \mathrm{~mL}$ volume). Test samples were added with the aforementioned buffer or ethanol by keeping the total volume. The tubes were sealed and kept at $60{ }^{\circ} \mathrm{C}$ in the dark. To the reaction mixture $(80 \mu \mathrm{L})$ were added $30 \%$ ammonium thiocyanate $(20 \mu \mathrm{L})$, and $20 \mathrm{mM}$ ferrous chloride solution $(20 \mu \mathrm{L})$. After $3 \mathrm{~min}$, the absorbance of the colored solution was measured at $500 \mathrm{~nm}$ with a Hitachi U-3900 spectrophotometer.<smiles>COC(=O)c1ccc(O)c(O)c1</smiles><smiles>COc1cc(C(=O)O)ccc1O</smiles>

3<smiles>COc1cc2c(c(OC)c1O)-c1ccc(O)cc1CC2</smiles>

2<smiles>O=c1c2cc(O)c(O)cc2oc2cc(O)c([C@@H]3O[C@H](CO)[C@@H](O)[C@H](O)[C@H]3O)c(O)c12</smiles>

Figure 1. The structures of $\mathbf{1}-\mathbf{4}$

Bioassay-Guided Isolation of 1-4: We discovered that the EtOAc extract of M. tenuifolia (flower) inhibited $\alpha$-glucosidase $(82.9 \%$ at $1 \mathrm{mg} / \mathrm{mL})$, when tested in an assay for $\alpha$-glucosidase inhibitory activity. This extract was subjected to $\alpha$-glucosidase activity-guided fractionation by using column chromatography on silica gel and the activity was limited to the fractions 3,9 and 10. Further purification processes led to yield four compounds, 3,4-dihydroxy benzoic acid methyl ester (1), flavanthridin (2), vanillic acid (3) and mangiferin (4)(Figure 1). All were identified by comparing spectroscopic properties with values previously reported in the literature [10-13]. Among them, 


\section{Anti-diabetic activity of $M$. tenuifolia}

mangiferin (4), a xanthone glucoside, is an active phytochemical present in various plants, with Anacardiaceae and Anemarrhena being two main resources [14]. Mangiferin has been reported to possess antibacterial [13], antitumor [15], antiviral [16] and immunomodulatory activities [17]. Interestingly, in this study, mangiferin (4) was the major constituent and approximately $31 \%$ weight of EtOAc extract of M. tenuifolia. The other three constituents (1), (2), and (3) have previously been isolated from several plants, but the hypoglycemic properties have not been previously reported.

3,4-Dihydroxy benzoic acid methyl ester (1): White powder. UV $\lambda \max (\mathrm{MeOH}) \mathrm{nm}: 224,275$. IR $v$ $(\mathrm{KBr}) \mathrm{cm}^{-1}: 1685,1604,1521,1438,1301 .{ }^{1} \mathrm{H}-\mathrm{NMR}(400 \mathrm{MHz}$, Acetone-d 6$): \delta 9.83(1 \mathrm{H}, \mathrm{s}, \mathrm{OH})$, $8.62(1 \mathrm{H}, \mathrm{s}, \mathrm{OH}), 7.46(1 \mathrm{H}, \mathrm{dd}, J=7.8,2.0 \mathrm{~Hz}, \mathrm{H}-6), 7.45(1 \mathrm{H}, \mathrm{d}, J=2.0 \mathrm{~Hz}, \mathrm{H}-2), 7.02(1 \mathrm{H}, \mathrm{d}, J=$ $7.8 \mathrm{~Hz}, \mathrm{H}-5), 3.94\left(3 \mathrm{H}, \mathrm{s}, \mathrm{OCH}_{3}\right)$.

Flavanthridin (2): White powder. UV $\lambda \max (\mathrm{MeOH}) \mathrm{nm}: 205$ (sh), 210 (sh), 230, 235 (sh). IR $v$ $(\mathrm{KBr}) \mathrm{cm}^{-1}: 3400,2910,1610,1490,1400,1230,1122,1076 .{ }^{1} \mathrm{H}-\mathrm{NMR}\left(400 \mathrm{MHz}\right.$, Acetone-d $\left.{ }_{6}\right): \delta$ $8.23(1 \mathrm{H}, \mathrm{d}, J=8.8 \mathrm{~Hz}, \mathrm{H}-4), 8.13(1 \mathrm{H}, \mathrm{s}, \mathrm{OH}), 7.88(1 \mathrm{H}, \mathrm{s}, \mathrm{OH}), 6.69(2 \mathrm{H}, \mathrm{m}, \mathrm{Ar}-\mathrm{H}), 6.46(1 \mathrm{H}, \mathrm{s}, \mathrm{Ar}-$ $\mathrm{H}), 3.85\left(3 \mathrm{H}, \mathrm{s}, \mathrm{OCH}_{3}\right), 3.79\left(3 \mathrm{H}, \mathrm{s}, \mathrm{OCH}_{3}\right), 2.67(4 \mathrm{H}, \mathrm{m}, \mathrm{H}-9, \mathrm{H}-10)$.

Vanillic acid (3): White powder. UV $\lambda \max (\mathrm{MeOH}) \mathrm{nm}: 203,225,289$. IR $v(\mathrm{KBr}) \mathrm{cm}^{-1}$ : 3400 2500, 1682, 1598, 1526, 1436, 1286. ${ }^{1} \mathrm{H}-\mathrm{NMR}$ (400 MHz, DMSO-d 6 ): $\delta 12.51(1 \mathrm{H}, \mathrm{br}, \mathrm{COOH})$, $9.86(1 \mathrm{H}, \mathrm{s}, 4-\mathrm{OH}), 7.43(1 \mathrm{H}, \mathrm{dd}, J=8.8,2.0 \mathrm{~Hz}, \mathrm{H}-6), 7.42(1 \mathrm{H}, \mathrm{d}, J=2.0 \mathrm{~Hz}, \mathrm{H}-2), 6.83(1 \mathrm{H}, \mathrm{d}, J=$ $8.8 \mathrm{~Hz}, \mathrm{H}-5), 3.80\left(3 \mathrm{H}, \mathrm{s}, \mathrm{OCH}_{3}\right)$.

Mangiferin (4): Pale yellow powder. UV $\lambda$ max (MeOH) nm: 246, 260, 333, 374. IR $v(\mathrm{KBr}) \mathrm{cm}^{-1}$ : 3500 2600, 2910, 1650, 1610, 1490, 1460, 1250, 1195. ${ }^{1} \mathrm{H}-\mathrm{NMR}$ (400 MHz, DMSO-d 6 ): $\delta 13.83$ $(1 \mathrm{H}, \mathrm{s}, 1-\mathrm{OH}), 7.32(1 \mathrm{H}, \mathrm{s}, \mathrm{H}-8), 6.79(1 \mathrm{H}, \mathrm{s}, \mathrm{H}-5), 6.34(1 \mathrm{H}, \mathrm{s}, \mathrm{H}-4), 4.57\left(1 \mathrm{H}, \mathrm{d}, J=9.6 \mathrm{~Hz}, \mathrm{H}-1{ }^{\prime}\right)$, $4.04\left(1 \mathrm{H}, \mathrm{dd}, J=9.6,9.2 \mathrm{~Hz}, \mathrm{H}-2^{\prime}\right), 3.67\left(1 \mathrm{H}, \mathrm{d}, J=11.2 \mathrm{~Hz}, \mathrm{H}-6{ }^{\prime} \mathrm{a}\right), 3.39(1 \mathrm{H}, \mathrm{dd}, J=11.2,4.8 \mathrm{~Hz}$, H-6'b), $3.18\left(1 \mathrm{H}, \mathrm{t}, J=9.2 \mathrm{~Hz}, \mathrm{H}-3^{\prime}\right), 3.12\left(2 \mathrm{H}, \mathrm{m}, \mathrm{H}-4{ }^{\prime}, \mathrm{H}-5^{\prime}\right) .{ }^{13} \mathrm{C}-\mathrm{NMR}\left(100 \mathrm{MHz}, \mathrm{DMSO}-\mathrm{d}_{6}\right): \delta$ 179.1 (C-9), 164.0 (C-3), 162.0 (C-1), 156.4 (C-4a), 155.6 (C-6), 151.3 (C-10a), 144.3 (C-7), 111.2 (C-8a), 107.8 (C-8), 107.6 (C-2), 102.5 (C-5), 101.4 (C-9a), 93.5 (C-4), 81.8 (C-5'), 79.2 (C-3'), 73.3 (C-1'), $70.9\left(\mathrm{C}-4^{\prime}\right), 70.4\left(\mathrm{C}-2^{\prime}\right), 61.7\left(\mathrm{C}-6^{\prime}\right)$.

$\alpha$-Glucosidase Inhibitory Activity: The inhibitory activities of the EtOAc extract of M. tenuifolia (MTE) in comparison with that of acarbose, the synthetic inhibitor of $\alpha$-glucosidase, as a reference compound were obtained (Figure 2). The inhibitory activity of the MTE was higher than that of acarbose with $82.9 \%$ inhibition. Science MTE displayed significant inhibition of $\alpha$-glucosidase activity, we analyzed which constituent from the extract was effective. At $1.0 \mathrm{mg} / \mathrm{mL}$ concentration, the four isolates 1-4 exhibited $22.9 \%, 96.7 \%, 81.0 \%$ and $59.9 \%$ inhibitory activity towards $\alpha$ glucosidase, respectively. In this assay flavanthridin (2) exhibited the most potent inhibitory activity of all tested compounds. Mangiferin (4), the major constituent of MTE, also showed the stronger activity of inhibition from $\alpha$-glucosidase. Notably, at $1.0 \mathrm{mg} / \mathrm{mL}$ concentration, acarbose had a lower ability to inhibit $\alpha$-glucosidase from Saccharomyces cerevisiae than MTE, 2, 3 and 4.

Assay for Antioxidative Activity: Anti-oxidant activity of MTE and the isolates 1-4 were determined in ferric thiocyanate method. In this assay, the inhibitory activity of linoleic acid peroxidation was determined and the antioxidant trolox (a water-soluble analogue of tocopherol) was assayed as a reference compound. Unsaturated fatty acids such as linoleic acid will be peroxided over time to hydroperoxides. In the presence of ferrous, lipid hydroperoxides convert ferrous iron to ferric form, and ferric ion subsequently coordinates with thiocyanate to generate ferric thiocyanate, increasing the absorption at $500 \mathrm{~nm}$. In our studies, 3,4-dihydroxy benzoic acid methyl ester (1) and mangiferin (4) showed total inhibition on the lipid peroxidation of the linoleic acid emulsion $(1.0 \mathrm{mg} / \mathrm{mL})$. In comparison, flavanthridin (2) and vanillic acid (3) exhibited much lower antioxidant activity (10.5\% and $15.5 \%$, respectively) (Figure 3). On the other hand, trolox (standard antioxidant) indicated an inhibition of $76.3 \%$ on peroxidation of linoleic acid emulsion. 
Li, Rec. Nat. Prod. (2022) 16:3 247-252

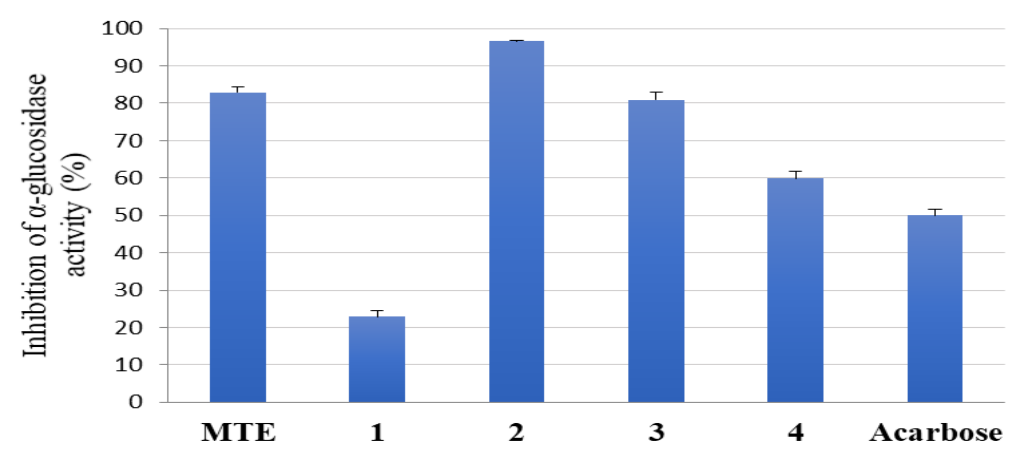

Figure 2. Inhibition of $\alpha$-glucosidase by $1 \mathrm{mg} / \mathrm{mL}$ of EtOAc extract of $M$. tenuifolia (MTE) and constituents 1-4. Acarbose acts as a positive control. The columns represent mean and standard deviation of three experiments

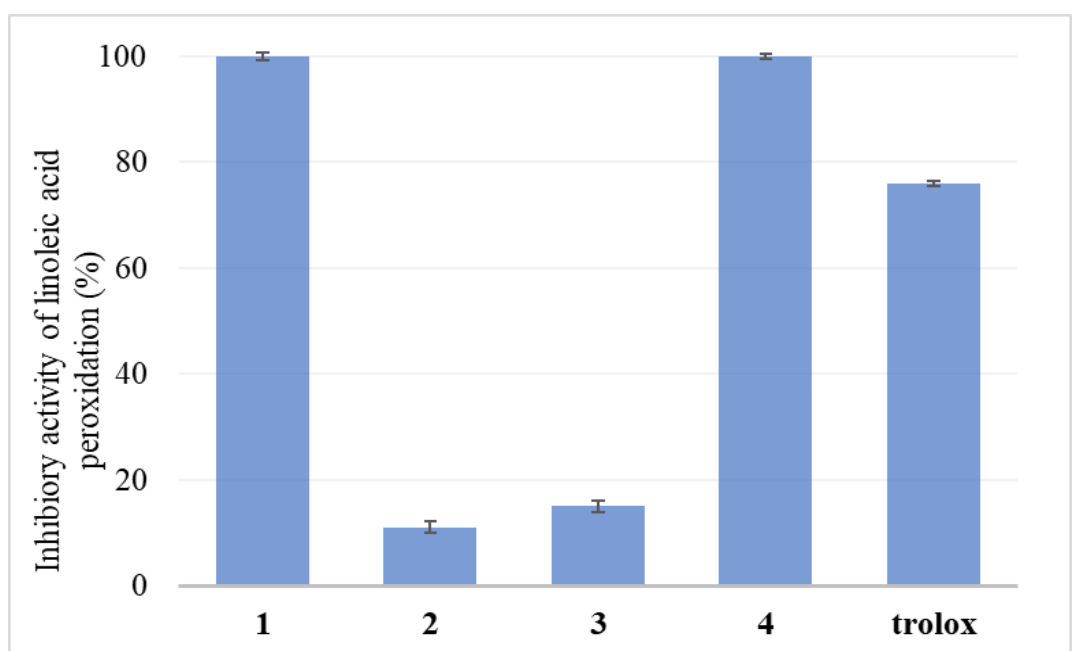

Figure 3. Inhibition of linoleic acid peroxidation by $1 \mathrm{mg} / \mathrm{mL}$ of constituents 1-4. Trolox acts as a positive control. The columns represent mean and standard deviation of three experiments

In conclusion, the EtOAc extract of M. tenuifolia (flower) is an effective inhibitor of $\alpha$ glucosidase and may function as an antihyperglycemic. To understand the inhibitive principle more clearly and to develop an antihyperglycemic drug, we purified and identified the active components from the extract and screened the $\alpha$-glucosidase inhibitive activity and antioxidative property. The results showed that the EtOAc extract of $M$. tenuifolia and the related constituents might have an antidiabetic effect by suppressing carbohydrate disintegration. Besides, mangiferin was reported for the first time from $M$. tenuifolia as a major constituent, indicated that $M$. tenuifolia can be used as a new source plant for mangiferin. This study also points out the potential use of $M$. tenuifolia extracting components could be antioxidants for health supplements and preventing damage to organisms by oxidative stress.

\section{Acknowledgments}

Appreciation is given to Lan Hui Biotech Co., for supplying Maxillaria tenuifolia material for this study.

\section{Supporting Information}

Supporting Information accompanies this paper on http://www.acgpubs.org/journal/records-ofnatural-products 


\section{ORCID}

Chia-Ying Li: $\underline{0000-0002-8319-5768}$

\section{References}

[1] S. Estrada, R. Toscano and R. Mata (1999). New phenanthrene derivatives from Maxillaria densa, J. Nat. Prod. 62, 1175-1178.

[2] N.A. Valencia-Islas, R.N. Paul, W.T. Shier, R. Mata and H.K. Abbas (2002). Phytotoxicity and ultrastructural effects of gymnopusin from the orchid Maxillaria densa on duckweed (Lemna pausicostata) frond and root tissues, Phytochemistry 61, 141-148.

[3] F. Perraudin, J. Popovici and C. Bertrand (2006). Analysis of headspace-solid microextracts from flowers of Maxillaria tenuifolia Lindl. by GC-MS, Electron. J. Nat. Substances 1, 1-5.

[4] S.Y. Kim, M. Ramya, H.R. An, P.M. Park, S.Y. Lee, S.Y. Park and P.H. Park (2019). Floral volatile compound accumulation and gene expression analysis of Maxillaria tenuifolia, Hortic. Sci. Technol. 37, 756-766.

[5] L.A. Bazzano, M. Serdula and S. Liu (2005). Prevention of type 2 diabetes by diet and lifestyle modification, J. Am. Coll. Nutr. 24, 310-319.

[6] F.A. Van de Laar, P.L. Lucassen, R.P. Akkermans, E.H. Van de Lisdonk, G.E. Rutten and C. Van Weel (2005). Alpha-glucosidase inhibitors for patients with type 2 diabetes: results from a Cochrane systematic review and meta-analysis, Diabetes Care 28, 154-163.

[7] M.S. Hedrington and S.N. Davis (2019). Considerations when using alpha-glucosidase inhibitors in the treatment of type 2 diabetes, Expert Opin. Pharmacother. 20, 2229-2235.

[8] Y.M. Kim, Y.K. Jeong, M.H. Wang, W.Y. Lee and H.I. Rhee (2005). Inhibitory effect of pine extract on alpha-glucosidase activity and postprandial hyperglycemia, Nutrition 21, 756-761.

[9] H.M. Chen, K. Muramoto and F. Yamauchi (1995). Structural analysis of antioxidative peptides from soybean $\beta$-conglycinin, J. Agric. Food Chem. 43, 574-578.

[10] C. He, Z. Shi, Q. Zhou, S. Li, N. Li and F. Huang (2008). Syntheses of cis- and trans-dibenzo-30crown-10 derivatives via regioselective routes and their complexations with paraquat and diquat, J. Org. Chem. 73, 5872-5880.

[11] J.S. Hwang, S.A. Lee, S.S. Hong, X.H. Han, C. Lee, S.J. Kang, D. Lee, Y. Kim, J.T. Hong, M.K. Lee and B.Y. Hwang (2010). Phenanthrenes from Dendrobium nobile and their inhibition of the LPSinduced production of nitric oxide in macrophage RAW 264.7 cells, Bioorg. Med. Chem. 20, 37853787.

[12] Q. Ren, W. Chen, H. Zhao, Z. Wu and H. Zhang (2012). Organic acids from Capparis spinosa fruit, Chem. Nat. Compd. 48, 868-869.

[13] T. Biswas, A. Sen, R. Roy, S. Maji and H.S. Maji (2015). Isolation of mangiferin from flowering buds of Mangifera indica $\mathrm{L}$ and its evaluation of in vitro antibacterial activity, J. Pharmaceu. Anal. 4, 49-56.

[14] M. Masibo and Q. He (2008). Major mango polyphenols and their potential significance to human health, Compr. Rev. Food Sci. Food Saf. 7, 309-319.

[15] S. Guha, S. Ghosal and U. Chattopadhyay (1996). Antitumor, immunomodulatory and anti-HIV effect of mangiferin, a naturally occurring glucosylxanthone, Chemotherapy 42, 443-451.

[16] C. Yoosook, N. Bunyapraphatsara, Y. Boonyakiat and C. Kantasuk (2000). Anti-herpes simplex virus activities of crude water extracts of Thai medicinal plants, Phytomedicine 6, 411-419.

[17] J. Leiro, J.A. Arranz, M. Yanez, F.M. Ubeira, M.L. Sanmartin and F. Orallo (2004). Expression profiles of genes involved in the mouse nuclear factor-kappa B signal transduction pathway are modulated by mangiferin, Int. J. Immunopharmacol. 4, 763-778.

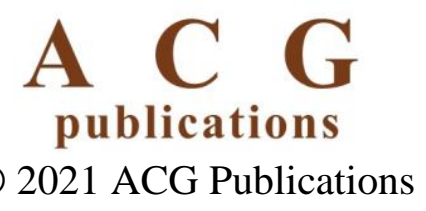

